\title{
DEVELOPMENT OF MARINE ENGINE PERFORMANCE PREDICTION MODEL THROUGH NEURAL NETWORK APPROACH
}

\author{
EZZATUL AZAMIN AND MOHD NOOR*
}

Faculty of Ocean Engineering Technology and Informatics, Universiti Malaysia Terengganu, 21030 Kuala Terengganu, Terengganu, Malaysia

*Corresponding author: che.wan@umt.edu.my

http://doi.org/10.46754/umtjur.2021.07.012

\begin{abstract}
The prediction and control of marine diesel engine performance and emission rates is not an easy task in real time. Comprehensive engine performance testing for entire operating conditions is extremely costly and time consuming. Therefore, the option of using a computer model can be used to determine those parameters. This work is concerned with the modeling of artificial neural networks in predicting the performance parameters of marine diesel engines such as torque, power, fuel consumption, efficiency and exhaust emission gases. Input data were obtained from engine tests in the laboratory operated with palm biodiesel and running at various speeds and loads. The predicted results have been validated by comparing the output values of the model with the experimental data. The results show that the prediction model using neural network gives good agreement to the experimental results which yield higher correlation coefficient of 0.98194 and lower mean square error of 0.0026809 . This study proves that a trained neural network model is capable to determine the performance of marine diesel engines in the accepted range.
\end{abstract}

Keywords: Neural network model, engine performance, marine engine

\section{Introduction}

In general, marine diesel engines are almost identical to regular diesel engines, but they are generallybulky, largerand producehigherthermal efficiency (Ashraful et al., 2014; Shukri et al., 2015)rising population, expanding urbanization, and economic growth in the world. To fulfill this energy demand, a large amount of fuel is widely used from different fossil resources. Burning of fossil fuels has caused serious detrimental environmental consequences. The application of biodiesel has shown a positive impact in resolving these issues. Edible vegetable oils are one of the potential feedstocks for biodiesel production. However, as the use of edible oils will jeopardize food supplies and biodiversity, non-edible vegetable oils, also known as second-generation feedstocks, are considered potential substitutes of edible food crops for biodiesel production. This paper introduces some species of non-edible vegetables whose oils are potential sources of biodiesel. These species are Pongamia pinnata karanja. The main source of energy to propel ships is the marine diesel engine, however its emissions is noted as one of the main sources of pollution in the marine environment (Borkowski, 2007; Fan et al., 2009). The most crucial seaborne emissions such as carbon monoxide, nitrogen oxides, particulate matter and sulphur oxides are formed as a result of marine fuel combustion. Approximately about $15 \%, 13 \%$, and $2.6 \%$ of the global emissions of $\mathrm{NO}_{\mathrm{x}}, \mathrm{SO}_{\mathrm{x}}$, and $\mathrm{CO}_{2}$, respectively are released from ships (Third IMO GHG study, 2014). In order to address this issue, rigorous emission limits have been imposed by various maritime organizations. The most recent Marine Pollution Act (MARPOL) states that the total sulphur emissions limit has been reduced from $3.50 \%$ to $0.50 \%$ which came into effect in January 2020. As a result, biodiesel which is derived from vegetable oil has gained attention as a potential alternative source for petroleum diesel fuel. Its primary advantages are renewable and biodegradable (Demirbas, 2009). Biodiesel is derived from the monoalkyl 
ester of vegetable oil. It can be processed from various plant sources such as soybean oil, palm, corn, sunflower and so on (How et al., 2014). To meet the strict ship discharge rules, intensive studies on diesel engines should be conducted. However, testing a marine diesel engine for overall operating conditions and fuel cases is costly and time consuming. Optionally, the ANN forecast model will be used to predict performance on marine diesel engines.
The ANN method is a computerized system that mimics the way of human brains function. Human brains are a huge network system that contains approximately 100 billion interconnected neurons (Von Bartheld et al., 2016). The ANN model contains interconnected nodes called artificial neurons that serve to transmit signals similar to the actual neuronal tasks in the human brain as shown in Figure 1 (Abraham, 2005).

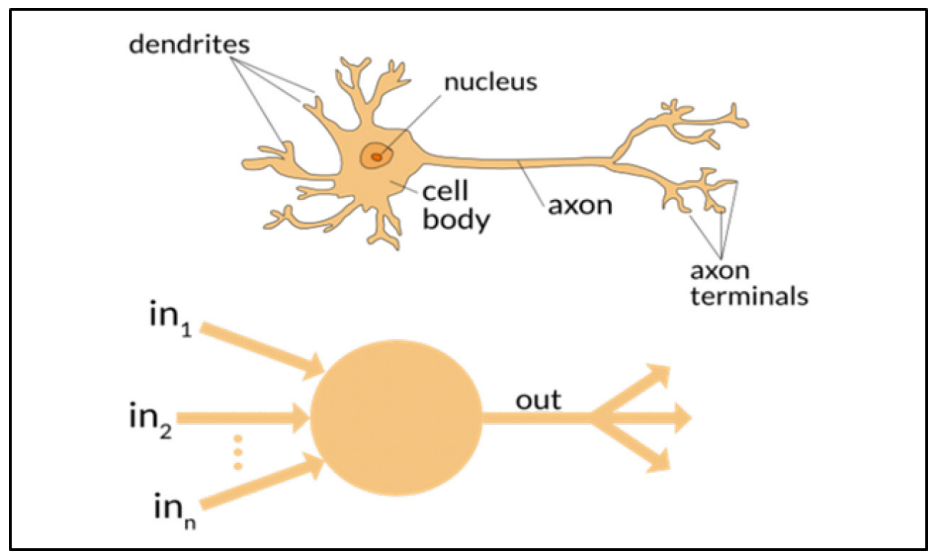

Figure 1: Neural network neuron

The ability of the ANN model is generated from training on actual data from experiments before making predictions for specific purposes. The predictive rate of a trained ANN model is much faster than a mathematical model simulation because it does not require differential equations but the selection of the appropriate number of neurons is essential for the accuracy of the prediction. The use of ANN methods in determining the performance of machines has been widely reported by researchers lately. The performance prediction of jatropha biodiesel in a Yanmar single-cylinder diesel engine was performed using ANN model (Dharma et al., 2017). The model gave excellent prediction result with higher R-values of 0.991-0.997 and lower error values between $0.4-1.2 \%$. The authors claimed that the ANN modelling was useful in biodiesel research as it has good generalisation capability and reliable to predict the engine performance.
Application of ANN method was used to predict the volumetric efficiency in a diesel engine (Luján et al., 2017). In this study, the results of engine mapping were used as input variables. The model yielded a small error prediction of $5.5 \%$ and sufficient coefficient of determination at $85 \%$. Another application of ANN was reported in a study to determine the performance and emission characteristics of hydrogen dual fuel engine (Syed et al., 2017). The model was trained by the trainbfg algorithm using eight neurons. The authors claimed that the ANN model was precisely predicting the experimental data with smaller error of 0.52 $4.35 \%$. In recent work, the ANN technique was employed to predict the cyclic variation of diesel-butanol blends (Gürgen et al., 2017). The authors reveal that the model provides high accuracy with the $\mathrm{R}$ value of $0.858-0.983$ and having smaller prediction error. Other ANN applications in the diesel engines studies were also reviewed (Bahri et al., 2017; Ganesan et al., 
2015; Ghanbari et al., 2017; Mohd Noor et al., 2016; Shukri et al., 2015)

From the literature, the application of ANN to marine diesel engines is still lacking and limited; therefore, this work is carried out to develop a predictive model on the performance of marine diesel engine using ANN method. This research consists of two stages, namely engine testing in the laboratory and the development of a predictive model. The data laboratory engine test will be used as input for the prediction model.

\section{Materials and Methods}

The implementation of the study was carried out in two stages, namely the engine experimental work and the development of the ANN model. The overall steps involved in completing this project are shown in Figure 2.

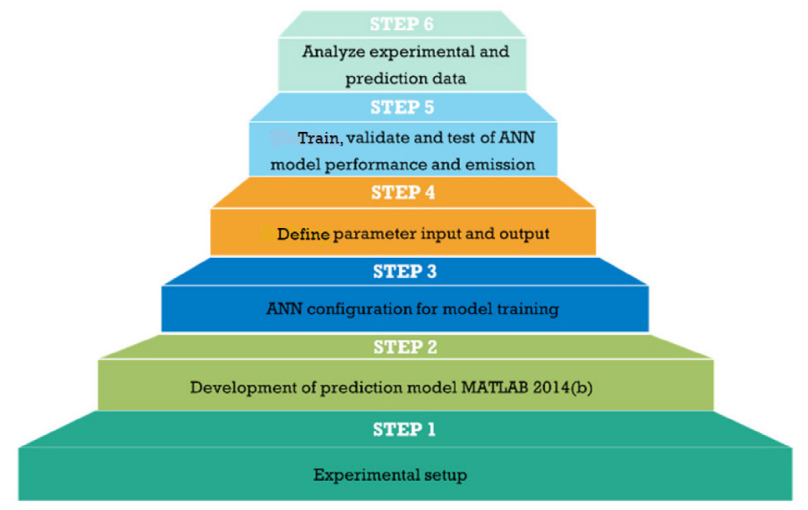

Figure 2: Reserch work procedure

The experiment carried out consists of the following work activities:

i. Preparing biodiesel fuels (BDF) from crude palm oil (CPO) base as well as their mixture with diesel fuel; percentage amount of fuel listed in Table 1

ii. Performing the engine test using the different types of biodiesel fuels iii. Quantifying the engine performance parameters such as torque, power, fuel consumption, efficiency and exhaust temperature

iv. Measuring the engine gas emissions released from the combustion of biodiesel such as nitrogen oxide (NOx) and carbon monoxide $(\mathrm{CO})$

Table 1: Percentage amount of fuel blend

\begin{tabular}{ccc}
\hline Fuel type & Diesel fuel (\%) & Palm Biodiesel fuel (\%) \\
\hline B0 & 100 & 0 \\
B10 & 90 & 10 \\
B20 & 80 & 20 \\
B30 & 70 & 30 \\
\hline
\end{tabular}

The laboratory testing experiments were conducted on four-stroke, $201 \mathrm{~kW}$, NTA-855 marine engine as shown in Figure 3. The fuel tested was a B10, B20, B30 blend of palm biodiesel and Standard diesel (B0) oil palm biodiesel. The tests were run under steady-state condition with different engine speed and loads. The engine exhaust emission was measured using KANE gas analyzer as shown in Figure 4. 


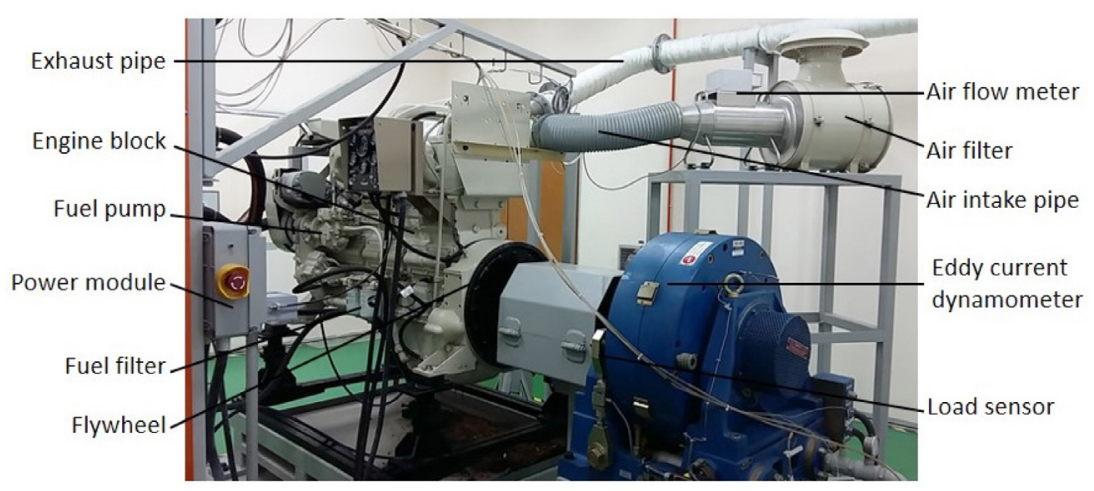

Figure 3: Cummins NT-855

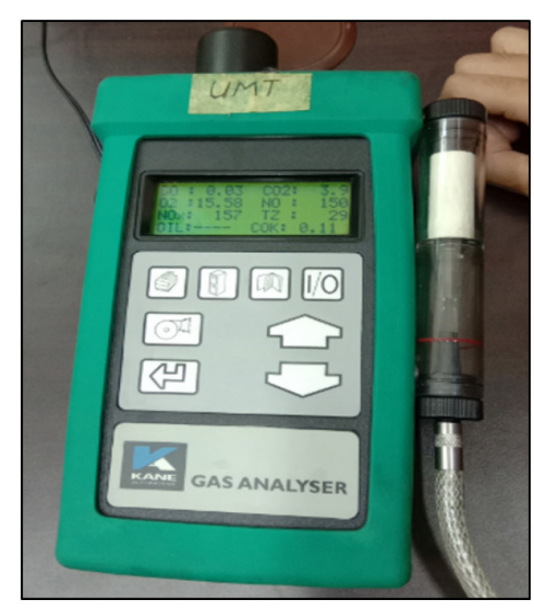

Figure 4: KANE gas analyzer

\section{Artificial Neural Network model}

The artificial neural network (ANN) prediction model was developed according to the flowchart as shown in Figure 5. The model has three layers which are input, hidden and output layers and the architecture of ANN structure is illustrated in Figure 6. The input parameters were type of fuel, engine load and speed whereas the output parameters consist of torque, power, thermal efficiency, exhaust temperature, specific fuel consumption, nitrogen oxide and carbon monoxide. The training algorithm used in this study was Levenberg-Marquardt. This algorithm operates using the Jacobian matrix and gradient vector method and is able to determine the minimum local point at an instantaneous rate. The Levenberg-Marquardt algorithm was proven to produce the fastest convergence value compared to other algorithms as reported by previous researchers (Kökkülünk et al., 2013; Mohd Noor et al., 2018). 


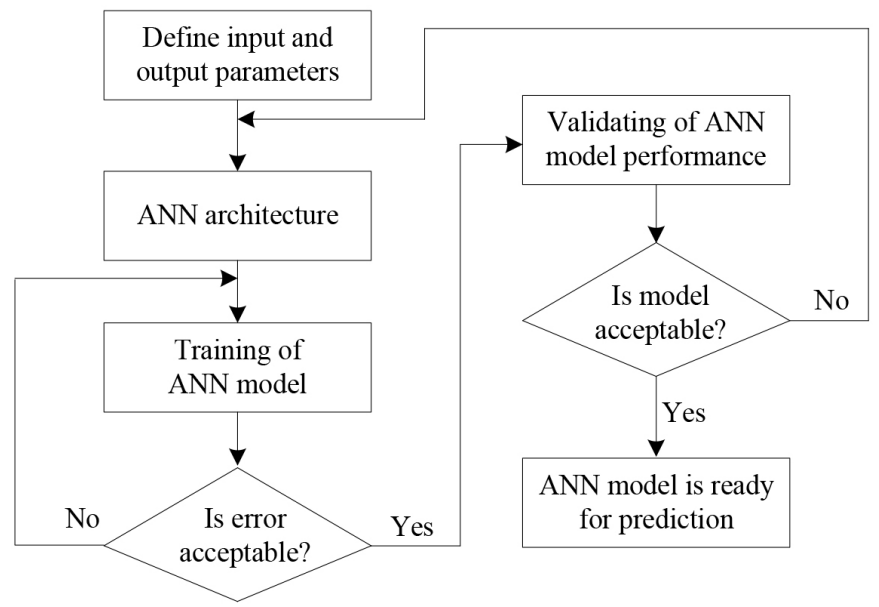

Figure 5: Prediction model flowchart

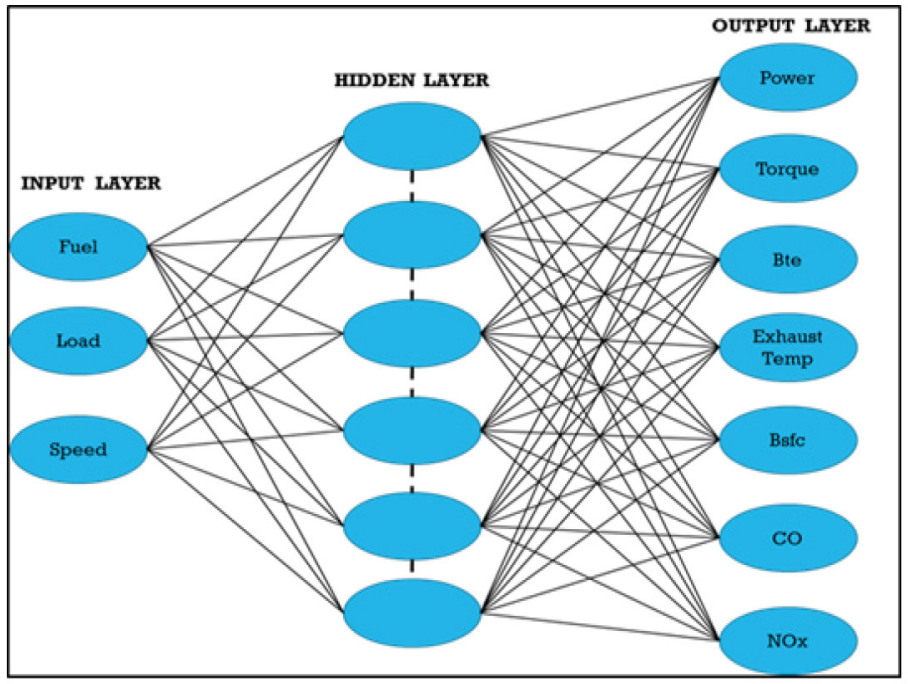

Figure 6: ANN architecture

Approximately $70 \%$ dataset were used in the training process, $15 \%$ in the validation and another $15 \%$ in the testing of ANN model as shown in Figure 7. The total number of datasets was1000 which were later divided into 700 for training, 150 for validation and another 150 for testing of the model. 


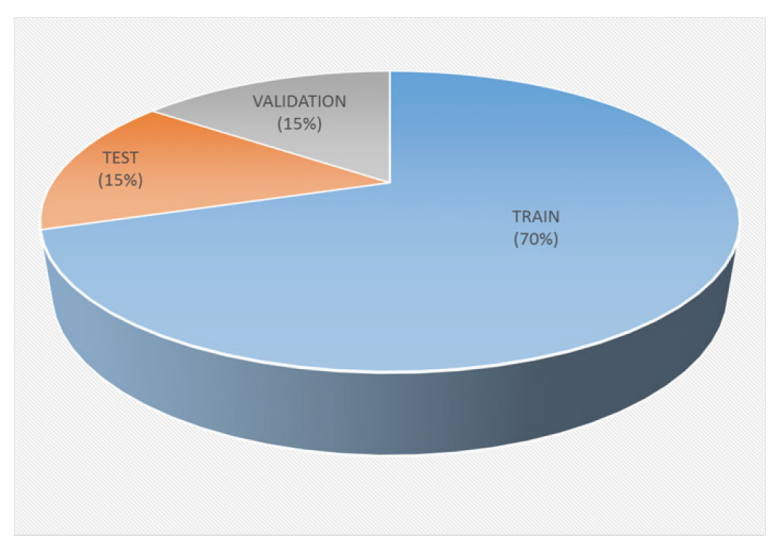

Figure 7: Dataset percentage for training, validation and test

The development and the training of prediction ANN model were conducted by using toolbox function in MATLAB software. Program script was added with the desired coding, including the number of hidden layers, transfer function and algorithm type used. Determining the best number of neuronal networks is a difficult task in ANN modeling. The final neural network configuration was listed in Table 2.

Table 2: Neural network model configuration

\begin{tabular}{cc}
\hline Parameter & Configuration \\
\hline No. of input neuron & 3 \\
No. of hidden neuron & 22 \\
No. of output neuron & 7 \\
Train algorithm & Levenberg-Marquardt \\
Model criteria & MSE \\
Model activation function & Tangent Hyperbolic \\
\hline
\end{tabular}

The process of determining the optimal architecture is done by experimenting with several numbers of neurons for the hidden layer. In this case, the neuron in the hidden layer was varied from 2 to 26 by trial and error procedure to determine the optimum number of neurons to be used. The result of mean square error (MSE) values and the correlation coefficients $(R)$ are also compared. The number of neurons that produced a value of $\mathrm{R}$, closest to 1 and has a low MSE value would be selected as the best number of neurons in the hidden layer.

Figure 8 shows that the best learning capability and the optimum condition occur at 22 numbers of neurons. MSE is defined as average squared difference between output and target and can be calculated using the equation (1). Lower value is better and if the value is 0 , it means there is no error. Figure 9 shows that the best validation performance is 0.0029057 , which occurs at epoch. Figure 10 illustrates the regression graph for training, validation and testing which measured the average correlation between output and target value which is at 0.98194 .

$$
M S E=\frac{1}{N} \sum N\left(y_{i}-y_{k}\right)^{2}
$$



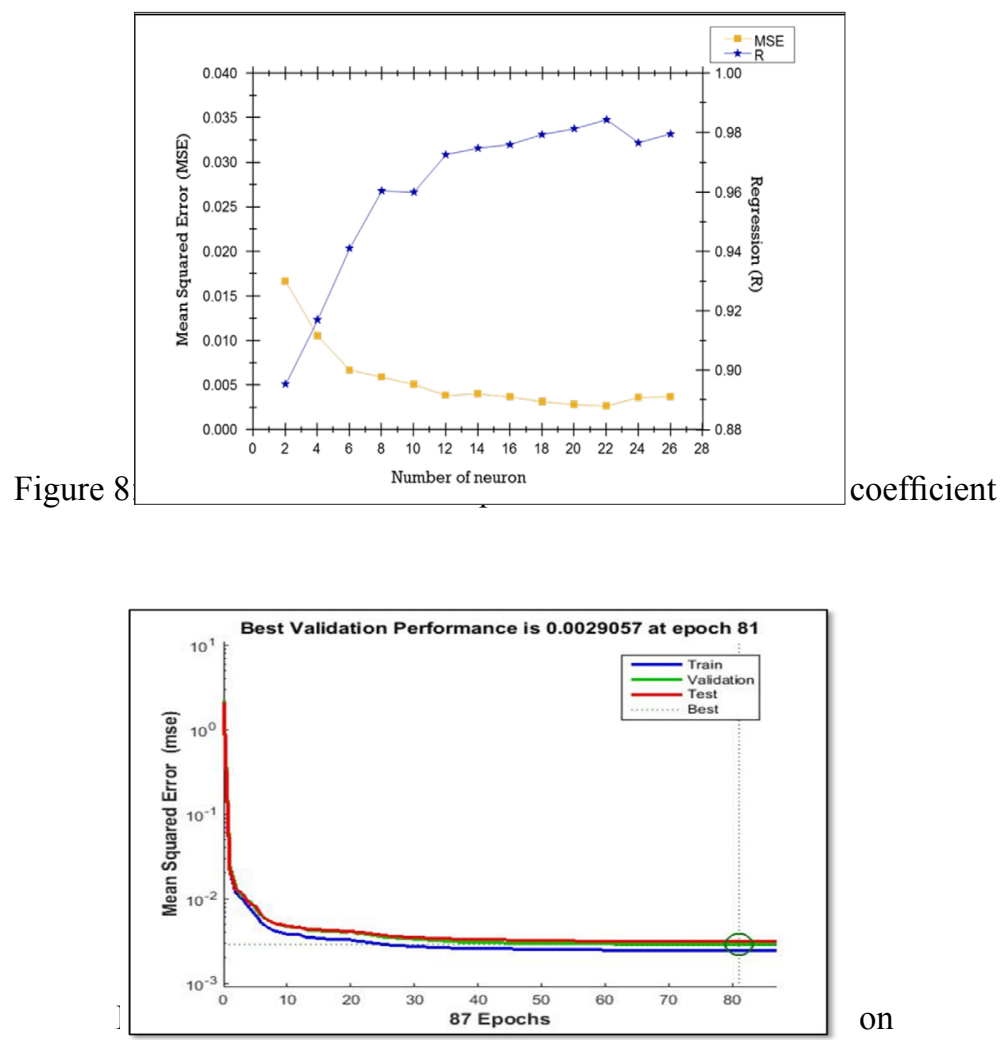

on

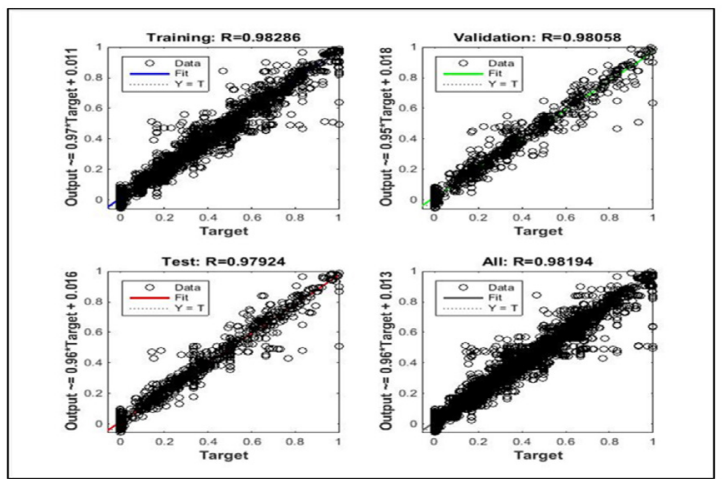

\section{Results and Discussion}

The engine performance and emission parameter that have been measured in this study consist of power, torque, brake thermal efficiency (BTE), exhaust gas temperature (EGT), brake specific fuel consumption (BSFC), nitrogen oxide (NOx) and carbon monoxide $(\mathrm{CO})$.

\section{ANN Model Validation}

The comparison of the ANN prediction results with the experiment data of marine diesel engine performance and emission are presented in Figure 11. The plots show a good agreement between the model prediction result and experiment data. The result clearly shows that the ANN prediction and the experimental result are close to each other for all output parameters. 


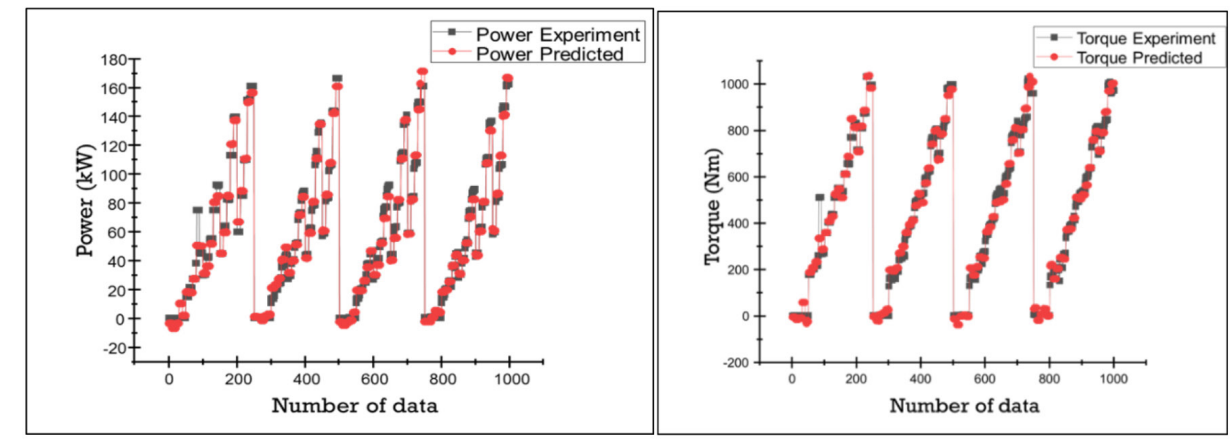

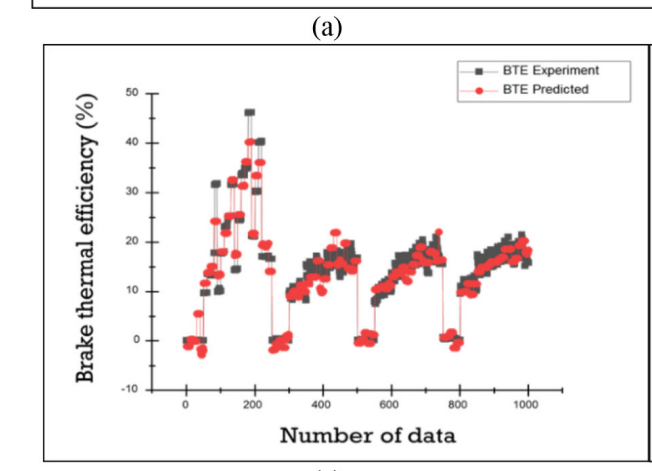

(c)

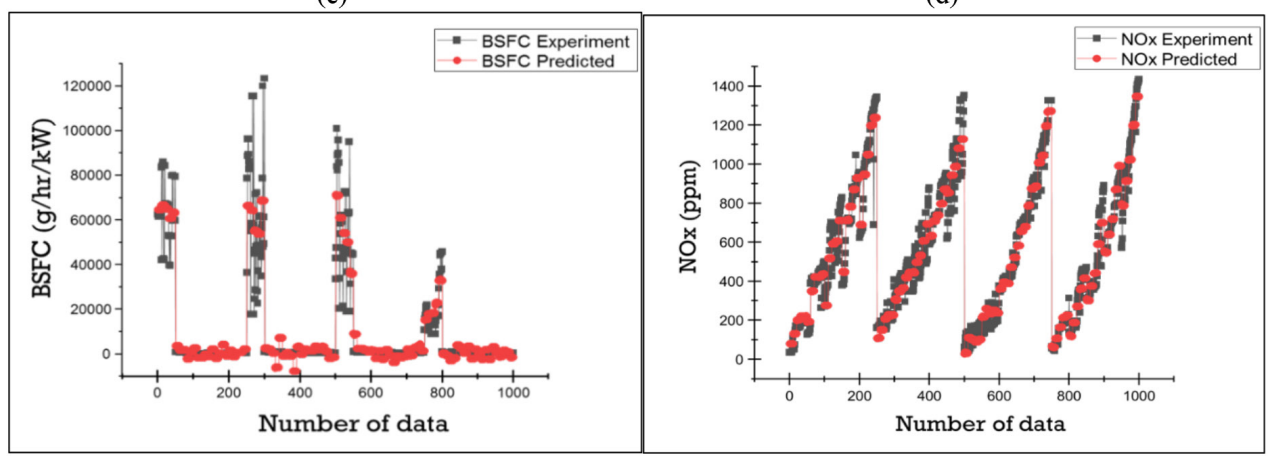

(e) (b)

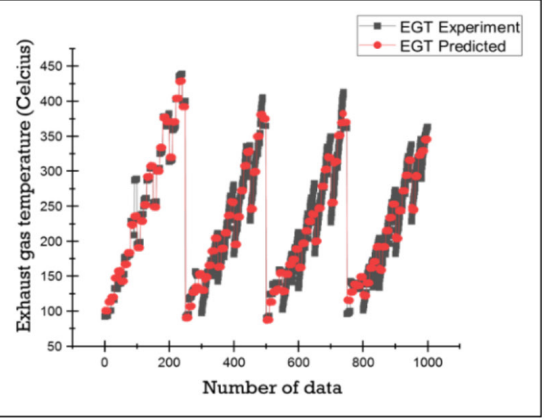

(d)

(f)

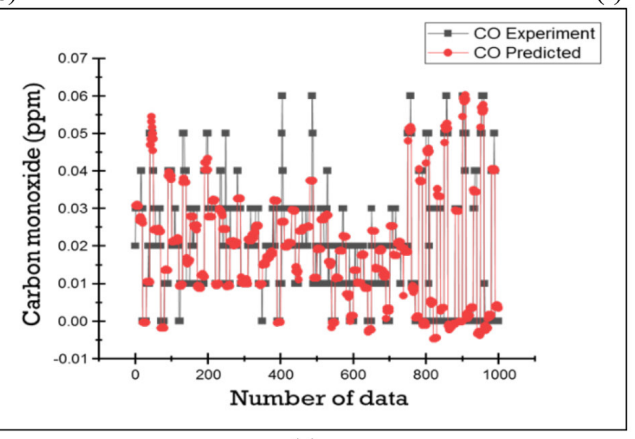

(g)

Figure 11: ANN prediction versus experiment for (a) power (b) torque (c) BTE (d) EGT (e) BSFC (f) $\mathrm{NO}_{\mathrm{x}}$ (g) $\mathrm{CO}$ 


\section{Correlation coefficient (R) of output parameter}

Correlation coefficient is measured on how close the correlation between output and target is. If the value is close to 1 , it means the model is accurate. The regression of $\mathrm{R}$ value shown in Figure 12 were generated by using equation 2 .

$$
R=1-\sqrt{\frac{\sum_{i=1}^{N}\left(y_{i}-y_{k}\right)^{2}}{\sum_{i=1}^{N}\left(y_{i}-\widetilde{y)^{2}}\right.}}
$$

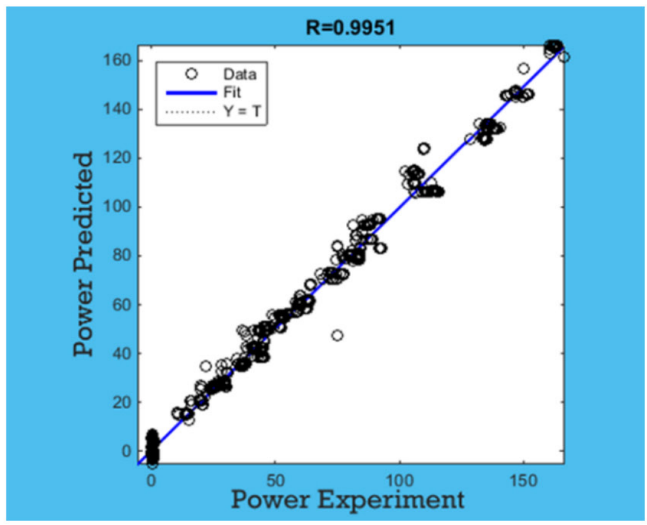

(a)

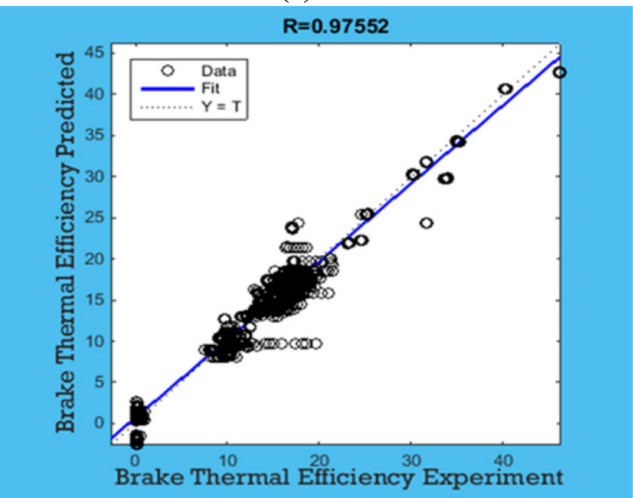

(c)

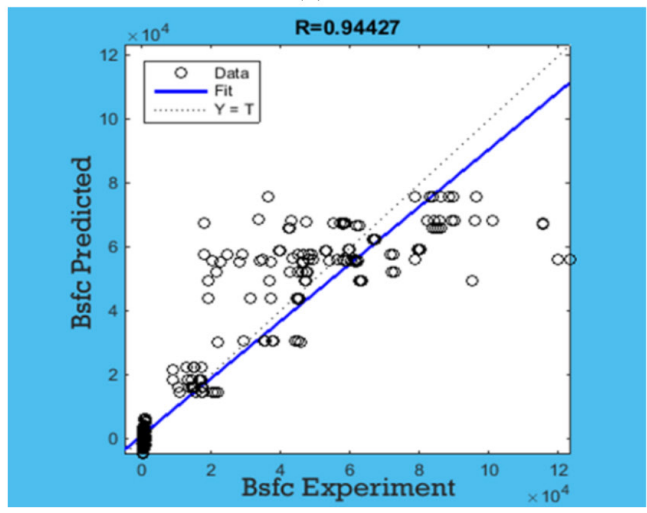

(e)

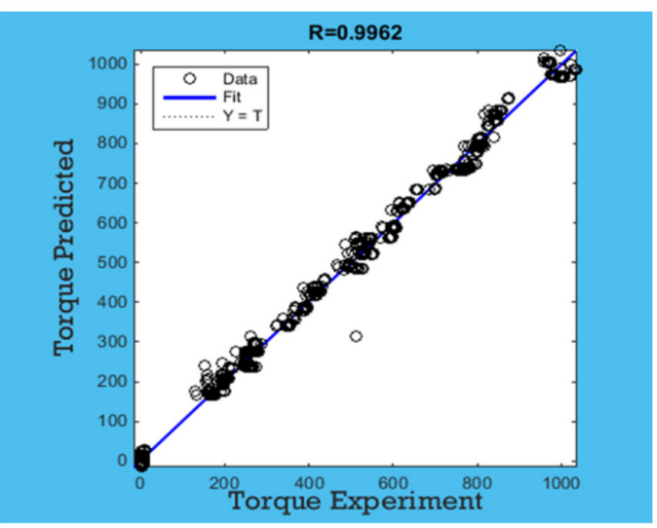

(b)

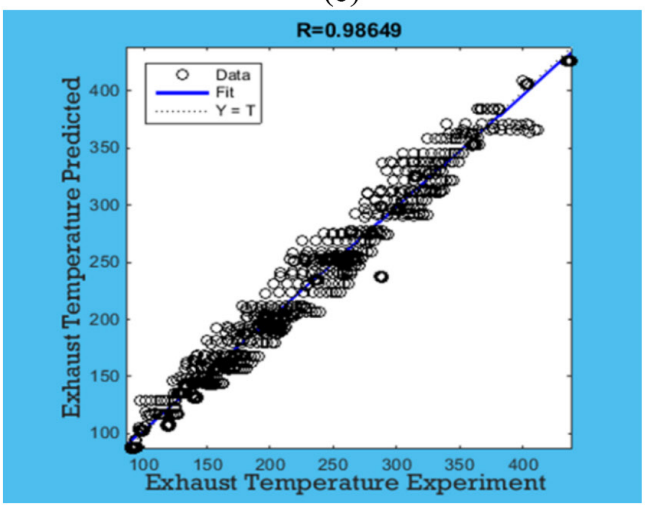

(d)

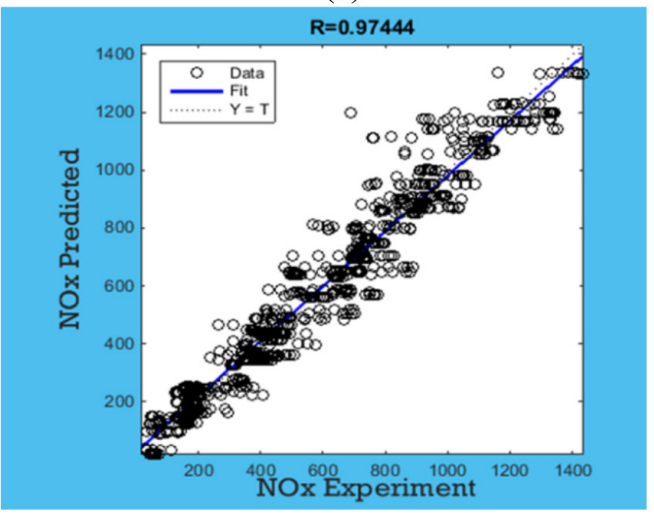

(f)

Figure 12: Correlation coefficient output parameter between experiment and ANN predict for (a) power (b) torque (c) BTE (d) EGT (e) BSFC (f) NOx (g) CO 
The ANN prediction model for the performance and emission of marine diesel engine provides a good correlation between output and target data. The correlation coefficient (R value) for power, torque, BTE, EGT, BSFC, NOx, and CO was 0.9951, 0.9962, 0.97552, $0.98649, \quad 0.94427,0.97444$, and 0.94707 respectively. The R value for BSFC 0.94427 and CO 0.94707 shows the lowest $R$ value due to slight inconsistency of the input data.

\section{Conclusion}

This study was carried out to develop a simulation model for prediction of marine diesel engine performance by utilizing ANN approach. The data from laboratory engine experiment were used as the input data. The performance and emission test consisting of four types of fuel B0, B10, B20 and B30, were run at various engine speed and loads. The training model with the 22 neurons produces the optimum prediction and provides a good agreement to the experiment data. The model produces a higher correlation coefficient of 0.98447 and it is lower, it means square error of 0.0026809 . In a nutshell, the artificial neural network model is capable of being used in nonlinear problems such as in predicting the performance of marine diesel engines as it can produce accurate output results compared to experimental results.

\section{Acknowledgements}

The main author would like to express deep and sincere gratitude to her research supervisor, Ts. Dr. C. W. Mohd Noor for giving the opportunity to do research and providing invaluable guidance throughout this study and many thanks also to the staff of the Maritime Technology laboratory for their cooperation in carrying out this work.

\section{References}

Abraham, A. (2005). Artificial Neural networks. In Handbook of Measuring System Design (pp. 901-908). John Wiley \& Sons, Ltd.
Ashraful, A. M., Masjuki, H. H., Kalam, M. A., Rizwanul Fattah, I. M., Imtenan, S., Shahir, S. A., \& Mobarak, H. M. (2014). Production and comparison of fuel properties, engine performance, and emission characteristics of biodiesel from various non-edible vegetable oils: A review. In Energy Conversion and Management 80, 202-228.

Bahri, B., Shahbakhti, M., \& Aziz, A. A. (2017). Real-time modeling of ringing in HCCI engines using artificial neural networks. Energy, 125, 509-518. https:// doi.org/10.1016/j.energy.2017.02.137

Borkowski, T. (2007). The NOx emission prediction in diesel exhaust for large bore marine engines. Journal of Polish CIMAC, 2(1), 85-92.

Demirbas, A. (2009). Progress and recent trends in biodiesel fuels. Energy Conversion and Management, 50(1), 14-34.

Dharma, S., Hassan, M. H., Ong, H. C., Sebayang, A. H., Silitonga, A. S., Kusumo, F., \& Milano, J. (2017). Experimental study and prediction of the performance and exhaust emissions of mixed Jatropha curcas-Ceiba pentandra biodiesel blends in diesel engine using artificial neural networks. Journal of Cleaner Production, 164, 618-633. https:// doi.org/10.1016/j.jclepro.2017.06.065

Fan, L., Zhu, Y., Long, W., Ma, X., \& Xue, Y. (2009). An investigation of the performance of an electronic in-line pump system for diesel engines. Journal of Marine Science and Application, 7(4), 261-267.

Ganesan, P., Rajakarunakaran, S., Thirugnanasambandam, M., \& Devaraj, D. (2015). Artificial neural network model to predict the diesel electric generator performance and exhaust emissions. Energy, 83, 115-124. https://doi.org/10.1016/j. energy.2015.02.094

Ghanbari, M., Najafi, G., Ghobadian, B., Yusaf, T., Carlucci, A. P., \& Kiani Deh Kiani, M. (2017). Performance and emission characteristics of a CI engine using nano 
particles additives in biodiesel-diesel blends and modeling with GP approach. Fuel, 202, 699-716. https://doi.org/10.1016/j. fuel.2017.04.117

Gürgen, S., Ünver, B., \& Altın, İ. (2017). Prediction of cyclic variability in a diesel engine fueled with n-butanol and diesel fuel blends using artificial neural network. Renewable Energy, 117, 538-544.

How, H. G., Masjuki, H. H., Kalam, M. A., \& Teoh, Y. H. (2014). An investigation of the engine performance, emissions and combustion characteristics of coconut biodiesel in a high-pressure common-rail diesel engine. Energy, 69, 749-759.

Kökkülünk, G., Akdogan, E., \& Ayhan, V. (2013). Prediction of emissions and exhaust temperature for direct injection diesel engine with emulsified fuel using ANN. Turkish Journal of Electrical Engineering and Computer Sciences, 21, 2141-2152. https://doi.org/10.3906/elk-1202-24

Luján, J. M., Climent, H., García-cuevas, L. M., \& Moratal, A. (2017). Volumetric efficiency modelling of internal combustion engines based on a novel adaptive learning algorithm of artificial neural networks. Applied Thermal Engineering, 123, 625-634. https://doi.org/10.1016/j. applthermaleng.2017.05.087

Mohd Noor, C. W., Mamat, R., \& Ahmed, A. N. (2018). Comparative study of artificial neural network and mathematical model on marine diesel engine performance prediction. International Journal of
Innovative Computing, Information and Control, 14(3), 959-969. http://www.ijicic. org/contents.htm

Mohd Noor, C. W., Mamat, R., Najafi, G., Mat Yasin, M. H., Ihsan, C. K., \& Noor, M. M. (2016). Prediction of marine diesel engine performance by using artificial neural network model. Journal of Mechanical Engineering and Sciences (JMES), 10(1), 1917-1930.

Shukri, M. R., Rahman, M. M., Ramasamy, D., \& Kadirgama, K. (2015). Artificial neural network optimization modeling on engine performance of diesel engine using biodiesel fuel. International Journal of Automotive and Mechanical Engineering (IJAME), 1(June), 2332-2347.

Syed, J., Baig, R. U., Algarni, S., Murthy, Y. V. V. S., Masood, M., \& Inamurrahman, M. (2017). Artificial Neural Network modeling of a hydrogen dual fueled diesel engine characteristics: An experiment approach. International Journal of Hydrogen Energy, 42(21), 14750-14774. https://doi. org/10.1016/j.ijhydene.2017.04.096

Third IMO GHG study. (2014). Third IMO Greenhouse Gas Study. Micropress Printers, Suffolk, UK. http://www.imo.org/

Von Bartheld, C. S., Bahney, J., \& HerculanoHouzel, S. (2016). The search for true numbers of neurons and glial cells in the human brain: A review of 150 years of cell counting. In Journal of Comparative Neurology (Vol. 524, Issue 18, pp. 38653895). https://doi.org/10.1002/cne. 24040 
